\title{
Herdabilidade dos teores de fibra alimentar e rendimento de grãos em populações de feijoeiro
}

\author{
Patrícia Medianeira Grigoletto Londero(1), Nerinéia Dalfollo Ribeiro(1), Alberto Cargnelutti Filho(2), \\ Josana de Abreu Rodrigues ${ }^{(1)}$ e Irajá Ferreira Antunes ${ }^{(3)}$
}

\begin{abstract}
(1)Universidade Federal de Santa Maria, Dep. de Fitotecnia, Camobi, CEP 97105-900 Santa Maria, RS. E-mail: patricia.Iondero@bol.com.br, neiadr@smail.ufsm.br, josanar@bol.com.br (2)Universidade Estadual Paulista, Fac. de Ciências Agrárias e Veterinárias, Dep. de Ciências Exatas, Via de Acesso Prof. Donato Castellane, s/no, CEP 14884-900 Jaboticabal, SP. E-mail: cargnelutti@fcav.unesp.br (3)Embrapa Clima Temperado, Caixa Postal 553, CEP 96001-000 Pelotas, RS. E-mail: iraja@cpact.embrapa.br
\end{abstract}

Resumo - O objetivo deste trabalho foi determinar a herdabilidade e o ganho na seleção para teor de fibra alimentar (solúvel, insolúvel e total) e para rendimento de grãos, em populações resultantes de cinco diferentes cruzamentos, além de identificar a população mais adequada, considerando-se as diferentes frações da fibra. Os cruzamentos entre os genitores CNFP 8100, FT 96-1282, Varre-Sai e Valente foram realizados em casa de vegetação. As populações obtidas (genitores, $F_{1}$ e $F_{2}$ ) foram avaliadas em campo, durante a primavera/verão de 2003/2004, em delineamento de blocos ao acaso. Diferenças significativas foram obtidas para fibra alimentar total; não foi detectada variabilidade genética para as frações da fibra - solúvel e insolúvel - e para rendimento de grãos nas populações. Correlação fenotípica positiva foi encontrada entre fibra insolúvel e fibra alimentar total. A seleção de plantas $\mathrm{F}_{2}$, em populações segregantes desenvolvidas a partir da combinação Valente x VarreSai, pode ser efetiva no desenvolvimento de germoplasma de feijão com maior teor de fibra alimentar total, em virtude da alta herdabilidade e maior ganho por seleção obtidos.

Termos para indexação: Phaseolus vulgaris, variância genética, ganho na seleção, correlação.

\section{Heritability of dietary fiber content and grain yield in common bean populations}

\begin{abstract}
The objective of this study was to estimate the heritability and gain from selection of dietary fiber content (soluble, insoluble and total) and grain yield, in populations obtained from five different crossings, and to identify more adequate population considering different fraction fibers. Crossings were performed in greenhouse among the genitors CNFP 8100, FT 96-1282, Varre-Sai and Valente. The populations obtained (parents, $\mathrm{F}_{1}$ and $\mathrm{F}_{2}$ ) were assessed in the field during spring/summer of 2003/2004, using a randomized complete blocks experimental design. Significant differences were obtained for total dietary fiber, however no genetic variability was observed for soluble and insoluble dietary fiber and grain yield in populations. Positive phenotypic correlation between insoluble and total dietary fiber was observed. $\mathrm{F}_{2}$ selection plants in segregant population, developed from Valente $x$ Varre-Sai, can be effective in the development of bean germplasm with higher total dietary fiber, because of the high broad-sense heritability estimates and highest gain from selection obtained in the combination.
\end{abstract}

Index terms: Phaseolus vulgaris, genetic variance, gain from selection, correlation.

\section{Introdução}

O feijão (Phaseolus vulgaris L.) é um dos mais importantes constituintes da dieta do brasileiro, por ser considerado um alimento de alto valor nutricional. Essa leguminosa é provida de quantidades significativas de proteínas, carboidratos, vitaminas, minerais e fibra, tem baixo conteúdo de gordura e de sódio e não contém colesterol (Hosfield, 1991; Morrow, 1991).

Fibras presentes nos alimentos são componentes importantes da dieta humana, e muitos países industria- lizados têm recomendado o incremento do consumo de fibra e a redução da ingestão de gordura (Topping, 1991), o que estaria associado a efeitos benéficos para o organismo.

Existem vários métodos para se determinar a fibra contida nos alimentos. O método oficial, adotado pelo Ministério da Agricultura, Pecuária e Abastecimento (Mapa), para a inscrição de cultivares de feijão no Serviço Nacional de Proteção de Cultivares (SNPC), é o de Weende, que considera a fibra bruta (Brasil, 2001). No entanto, esse método não é mais aceito no fornecimento 
de dados para a alimentação humana, uma vez que leva a um erro grave na estimativa do valor nutritivo do alimento. Assim, o método enzímico-gravimétrico, que considera a fibra alimentar e quantifica as diferentes frações da fibra solúvel e insolúvel, é o mais indicado, porque utiliza enzimas e se aproxima mais do processo de digestão humana.

A fibra alimentar pode ser classificada, quanto à sua solubilidade, em fibra solúvel e fibra insolúvel. A fibra solúvel é composta por substâncias pécticas, gomas, hemiceluloses e b glucanas, enquanto a fração insolúvel é composta por celulose, lignina e a maioria das hemiceluloses (Guerra et al., 2004).

As frações que compõem a fibra alimentar exercem efeitos fisiológicos distintos no organismo humano. As fibras solúveis têm a propriedade de diminuir a absorção da glicose e do colesterol plasmático, e as fibras insolúveis aceleram o tempo de trânsito intestinal, auxiliando na prevenção de doenças do trato gastrintestinal (Olson et al., 1987; Moore et al., 1998; Vanderhoof, 1998). O feijão é um dos poucos alimentos que possui conteúdo balanceado de ambas as frações de fibra (Hughes, 1991), o que torna o seu consumo vantajoso para a saúde humana.

O grão de feijão é composto pelo tegumento, que representa cerca de $9 \%$ na matéria seca, cotilédones, com 90\%, e eixo embrionário, apenas 1\% (Mesquita, 1989). Há indicativos de que a fibra se concentra em maior quantidade no tegumento (Egg Mendonça, 2001). Como o tegumento é tecido materno - desenvolvido a partir da parede do óvulo - o genótipo da geração $F_{1}$ representará o genótipo materno; ou seja, o genótipo da $\mathrm{F}_{1}$ somente se expressará em $F_{2}$ (Ramalho et al., 2000). Assim, a geração $F_{1}$ apenas representaria os produtos da fertilização, se a maior concentração de fibra fosse encontrada nos cotilédones, pois esses tecidos estão em gerações diferentes.

Oliveira et al. (1999) encontraram valores de 15,83\% de fibra alimentar total (FAT), 12,40\% de fibra insolúvel (FI) e 3,43\% de fibra solúvel (FS) em feijão vermelho. Becker et al. (1986) observaram teores de 19,8\% de FAT, 9,6\% de FI e 10,2\% de FS em feijão branco. Podese, portanto, inferir que há variabilidade genética, e essa é condição essencial, para que o melhorista possa exercer pressão de seleção artificial e obter o ganho esperado (Coimbra et al., 1999).
No entanto, para que seja possível o estabelecimento de critérios de seleção, para se aumentar o teor de fibra alimentar em grãos de feijão, é necessário o conhecimento da herdabilidade e do ganho por seleção. $\mathrm{O}$ estudo de um determinado caráter começa a partir da herdabilidade, que possibilita prever o ganho a ser obtido na próxima geração e, com isso, alcançar genótipos superiores (Carvalho et al., 2001). Com a estimativa do ganho, pode-se avaliar a eficiência dos métodos de melhoramento, bem como o êxito do material melhorado (Cruz \& Regazzi, 1997).

O desafio para o melhoramento genético está no desenvolvimento de genótipos com teores diferenciados em quantidade de fibra solúvel e insolúvel, para tornar o feijão um alimento funcional e de alta qualidade, o que possibilitaria maiores benefícios à alimentação da população brasileira. Contudo, um dos aspectos menos estudados da composição química dos grãos de feijão, produzidos no Brasil, é a fibra alimentar e suas frações. Até o presente, não há dados, na literatura, sobre avaliação da variabilidade genética e de parâmetros genéticos desse componente nutricional. Assim, há necessidade do conhecimento das estimativas de herdabilidade e do ganho de seleção dessa característica, visando ao desenvolvimento de genótipos com qualidade química superior.

O objetivo deste trabalho foi estimar a herdabilidade e o ganho na seleção para teor de fibra solúvel, fibra insolúvel, fibra alimentar total e rendimento de grãos, bem como estudar a correlação entre essas características, em populações obtidas de cinco diferentes cruzamentos entre genótipos brasileiros de feijão, e identificar a população considerada promissora para a seleção de maiores teores de fibras e alto rendimento de grãos.

\section{Material e Métodos}

Um experimento prévio foi conduzido em campo, no ano agrícola de 2001/2002, para a quantificação do teor de fibra em grãos pertencentes ao Banco de Germoplasma de Feijão, da Universidade Federal de Santa Maria, RS. Assim, com base no teor de fibra e no desempenho dos genótipos em campo (produtividade, arquitetura de planta e outros descritores agromorfológicos de importância), selecionaram-se quatro genitores (CNFP 8100, FT 96-1282, Valente e 
Varre-Sai). Esses foram cruzados aos pares, com exceção da combinação CNFP 8100 x Valente, segundo a metodologia de dialelos completos, sem se considerar os recíprocos (Cruz \& Regazzi, 1997).

As hibridações controladas foram realizadas durante o ano de 2003, em casa de vegetação, com a utilização da técnica sem emasculação, descrita em Peternelli \& Borém (1999). Os blocos de cruzamentos foram conduzidos em vasos de plástico, com capacidade para $5 \mathrm{~kg}$ de solo, com duas plantas por vaso. A fim de garantir o desenvolvimento normal das plantas de feijão, foram realizadas irrigações diárias, controle de doenças e de insetos e adubação nitrogenada em cobertura, sempre que necessário. À medida que as vagens de feijão atingiram a maturação fisiológica, foi realizada a colheita individualizada das vagens de cada população.

Considerando-se que a fibra alimentar está presente no tegumento dos grãos de feijão, a geração $F_{1}$ representa o genótipo materno, e sua expressão será possível em $\mathrm{F}_{2}$; o genótipo da geração $\mathrm{F}_{2}$ se expressará somente em $\mathrm{F}_{3}$ (Ramalho et al., 2000; Egg Mendonça, 2001). Assim, as sementes $F_{2}$ representam a expressão da $F_{1}$ - geração $F_{1}$, e as sementes $F_{3}$ representam a expressão da $F_{2}$ - geração $F_{2}$. As populações obtidas (genitores, geração $F_{1}$ e $F_{2}$ ) foram avaliadas em campo, em solo caracterizado como Alissolo Hipocrômico argilúvico típico.

O delineamento experimental utilizado foi o de blocos ao acaso, com duas repetições, e a semeadura ocorreu em 21 de novembro de 2003. As parcelas foram constituídas de uma linha de $1 \mathrm{~m}$ de comprimento, com 10 plantas por metro linear para os genitores e para as populações $F_{1}$. Para as populações $F_{2}$ usaram-se parcelas maiores, duas linhas de $1 \mathrm{~m}$, em virtude da maior variabilidade genética das plantas.

O solo foi preparado de forma convencional, e a adubação foi realizada no sulco de semeadura, de acordo com a interpretação da análise química do solo. A adubação nitrogenada em cobertura foi parcelada em duas aplicações de $40 \mathrm{~kg} \mathrm{ha}^{-1}$ de nitrogênio, nos estádios vegetativos V3 e V4, primeira e terceira folhas trifolioladas, respectivamente. Os tratos culturais como controle de insetos e de plantas invasoras foram realizados, sempre que necessário, de maneira que a cultura não sofresse competição (Cepef, 2003).

A colheita e a triagem das plantas foram realizadas manualmente e, depois da retirada das impurezas, os grãos foram secados ao sol e em estufa, até atingir umidade média de $12 \%$, tendo-se quantificado o rendimento de grãos em grama por planta. Amostras de $20 \mathrm{~g}$ de grãos, de cada população, foram preparadas para as análises de fibra alimentar, realizada segundo a metodologia descrita pela AOAC (1995), que determina analiticamente os teores de fibra alimentar total e insolúvel e quantifica, por diferença, o teor da fibra solúvel da amostra.

Os dados das variáveis teores de fibra solúvel, fibra insolúvel, fibra alimentar total e rendimento de grãos, das quatro gerações ( $\mathrm{P} 1, \mathrm{P} 2, \mathrm{~F}_{1}$ e $\mathrm{F}_{2}$ ), de cada uma das cinco combinações entre os genitores, foram submetidos à análise da variância e teste F. Realizou-se a análise de correlação linear de Pearson entre as variáveis, em cada combinação e geral. Fez-se a análise de gerações (P1, P2, F1 e $\left.F_{2}\right)$ em cada uma das cinco combinações (Cruz, 2001), tendo-se obtido as estimativas dos parâmetros genéticos, nas populações $\mathrm{F}_{2}$, e a predição do ganho baseado na seleção de dois indivíduos da geração $F_{2}$, conforme metodologia descrita em Cruz \& Regazzi (1997). As análises foram realizadas com o auxílio do programa Genes (Cruz, 2001).

\section{Resultados e Discussão}

Os dados de fibra solúvel, fibra insolúvel e rendimento de grãos não apresentaram diferença significativa entre as combinações, o que indica que não foi possível a identificação de variabilidade genética entre as gerações (Tabela 1). Para a fibra alimentar total, apenas na combinação Valente $x$ Varre-Sai foi observada diferença significativa.

O teor de fibra solúvel variou de 8,04 a $11,11 \%$, e o teor de fibra insolúvel variou de 24,82 a 31,35\%, podendo-se inferir que cerca de $1 / 4$ da fibra alimentar presente em grãos de feijão preto é fração solúvel, enquanto 3/4 é fração insolúvel (Tabela 2).

A fibra alimentar total variou de 33,39 a 39,39\% (Tabela 2). Apenas na combinação Valente x Varre-Sai foram obtidas populações segregantes, com maiores teores de fibra alimentar total, o que sugere que um germoplasma superior poderá ser identificado em gerações mais avançadas do programa de melhoramento. No entanto, como foram utilizados genitores contrastantes, classificados em experimento prévio com alta FAT - valores superiores a $37 \%$ - e baixa FAT valores inferiores a 35\% (Londero et al., 2005), espera- 
va-se que fosse observada variabilidade genética. Supõe-se que a inclusão dos valores médios das populações $F_{2}$, geração com maior variabilidade genética e heterogeneidade de plantas, tenha contribuído para aumentar o erro experimental e, como conseqüência, acrescer a diferença mínima significativa entre as médias das populações. Além disso, o efeito materno, na expressão de um determinado caráter nos descendentes, poderá ocorrer por uma ou duas gerações (Ramalho et al., 2001).

Em feijão vermelho, após cozimento por 40 minutos em panela de pressão, o teor de fibra alimentar total encontrado foi de $15,8 \%$, dos quais $12,4 \%$ de fibra insolúvel e 3,4\% de fibra solúvel (Oliveira et al., 1999). Em feijão branco, 19,8\% de fibra alimentar total foi quantificada pelo método de Berlin, com 9,6\% de fibra insolúvel e 10,2\% de fibra solúvel (Becker et al., 1986), o que sugere que pode ser encontrada variabilidade genética para teor de fibra alimentar, em grãos de feijão de diferentes grupos comerciais. No entanto, não é possível a comparação dos dados obtidos neste trabalho com os citados em feijão vermelho e branco, porque esses trabalhos utilizaram diferentes metodologias para a determinação da fibra alimentar.

Foi obtido, no conjunto das combinações, coeficiente de correlação fenotípico negativo $(r=-0,48)$ entre a fibra solúvel e fibra insolúvel, e resposta semelhante foi observada apenas na combinação entre CNFP 8100 x FT 96-1282 (Tabela 3). Assim, quando se considera a média geral das populações avaliadas, pode-se inferir que, à medida que ocorre o incremento no teor de fibra solúvel, há a diminuição do teor de fibra insolúvel, o que pode dificultar o incremento de ambas as frações da fibra (solúvel e insolúvel) em genótipos de feijão.

Os coeficientes de correlação fenotípicos, obtidos entre a fibra insolúvel e a fibra alimentar total, foram positivos $(r=0,68$ a 0,93$)$ nas diferentes combinações $e$ no conjunto das combinações (Tabela 3). Esse resultado

Tabela 1. Graus de liberdade (GL) e quadrado médio em relação à fibra solúvel, fibra insolúvel, fibra alimentar total e rendimento de grãos de feijoeiro para as causas de variação, média e coeficiente de variação $(C V)$, nas quatro gerações $\left(P 1, P 2, F_{1}\right.$ e $\left.F_{2}\right)$, em diferentes combinações.

\begin{tabular}{|c|c|c|c|c|c|c|}
\hline \multirow[t]{3}{*}{ Causa de variação } & \multirow[t]{3}{*}{ GL } & \multicolumn{5}{|c|}{ Combinação } \\
\hline & & CNFP $8100 \mathrm{x}$ & CNFP $8100 \mathrm{x}$ & FT 96-1282x & FT 96-1282 x & Valente $\mathrm{x}$ \\
\hline & & FT 96-1282 & Varre-Sai & Valente & Varre-Sai & Varre-Sai \\
\hline & \multicolumn{6}{|c|}{ Fibra solúvel (\%) } \\
\hline Blocos & 3 & $2,58^{\mathrm{ns}}$ & $0,64^{\mathrm{ns}}$ & $2,42^{\text {ns }}$ & $11,73^{\mathrm{ns}}$ & $5,16^{\mathrm{ns}}$ \\
\hline Geração & 3 & $2,22^{\mathrm{ns}}$ & $0,51^{\mathrm{ns}}$ & $3,15^{\mathrm{ns}}$ & $4,93^{\text {ns }}$ & $2,65^{\mathrm{ns}}$ \\
\hline Erro & 3 & 1,84 & 0,48 & 5,95 & 2,01 & 4,80 \\
\hline Média & - & 8,85 & 9,08 & 9,55 & 9,00 & 9,01 \\
\hline \multirow[t]{2}{*}{$\mathrm{CV}(\%)$} & - & 15,33 & 7,65 & 25,55 & 15,75 & 24,31 \\
\hline & \multicolumn{6}{|c|}{ Fibra insolúvel (\%) } \\
\hline Blocos & 3 & $0,61^{\mathrm{ns}}$ & $6,86^{\mathrm{ns}}$ & $18,69^{\text {ns }}$ & $3,07^{\text {ns }}$ & $8,08^{\mathrm{ns}}$ \\
\hline Geração & 3 & $8,29^{\text {ns }}$ & $10,37^{\mathrm{ns}}$ & $5,26^{\mathrm{ns}}$ & $2,88^{\mathrm{ns}}$ & $5,44^{\mathrm{ns}}$ \\
\hline Erro & 3 & 17,46 & 2,71 & 6,93 & 12,87 & 5,94 \\
\hline Média & - & 28,24 & 27,75 & 25,73 & 26,82 & 27,44 \\
\hline \multirow[t]{2}{*}{$\mathrm{CV}(\%)$} & - & 14,80 & 5,93 & 10,24 & 13,38 & 8,88 \\
\hline & \multicolumn{6}{|c|}{ Fibra alimentar total (\%) } \\
\hline Blocos & 3 & $1,86^{\mathrm{ns}}$ & $8,86^{\mathrm{ns}}$ & $10,67^{*}$ & $4,56^{\mathrm{ns}}$ & $12,04^{*}$ \\
\hline Geração & 3 & $6,51^{\mathrm{ns}}$ & $9,70^{\mathrm{ns}}$ & $1,84^{\mathrm{ns}}$ & $2,04^{\mathrm{ns}}$ & $12,63^{*}$ \\
\hline Erro & 3 & 8,06 & 2,14 & 0,78 & 19,67 & 0,22 \\
\hline Média & - & 37,09 & 36,83 & 35,27 & 35,82 & 36,46 \\
\hline \multirow[t]{2}{*}{$\mathrm{CV}(\%)$} & - & 7,66 & 3,97 & 2,50 & 12,38 & 1,29 \\
\hline & \multicolumn{6}{|c|}{ Rendimento de grãos (g planta $\left.{ }^{-1}\right)$} \\
\hline Blocos & 3 & $8,09^{*}$ & $18,53^{\mathrm{ns}}$ & $14,93^{\mathrm{ns}}$ & $19,34^{\mathrm{ns}}$ & $11,17^{\mathrm{ns}}$ \\
\hline Geração & 3 & $3,80^{\mathrm{ns}}$ & $13,87^{\mathrm{ns}}$ & $5,39^{\text {ns }}$ & $8,38^{\text {ns }}$ & $13,04^{\mathrm{ns}}$ \\
\hline Erro & 3 & 0,43 & 33,10 & 10,66 & 14,54 & 41,96 \\
\hline Média & - & 11,59 & 12,65 & 13,26 & 13,68 & 16,12 \\
\hline CV $(\%)$ & - & 5,64 & 45,49 & 24,62 & 27,88 & 40,18 \\
\hline
\end{tabular}

nsNão-significativo. * Significativo a 5\% de probabilidade pelo teste F. 
Tabela 2. Médias \pm desvio padrão, valor mínimo e máximo do teor de fibra solúvel, fibra insolúvel, fibra alimentar total e rendimento de grãos de feijoeiro, nas quatro gerações (P1, P2, $\mathrm{F}_{1}$ e $\left.\mathrm{F}_{2}\right)$, em diferentes combinações.

\begin{tabular}{|c|c|c|c|c|c|}
\hline \multirow[t]{2}{*}{ Geração $^{(1)}$} & \multicolumn{5}{|c|}{ Combinação } \\
\hline & CNFP $8100 \times$ FT 96-1282 & CNFP 8100 x Varre -Sai & FT 96-1282 x Valente & FT 96-1282 x Varre-Sai & Valente x Varre -Sai \\
\hline & \multicolumn{5}{|c|}{ Fibra solúvel (\%) } \\
\hline P1 & $10,00 \pm 0,49 \mathrm{a}$ & $10,00 \pm 0,49 \mathrm{a}$ & $8,87 \pm 0,08 \mathrm{a}$ & $8,87 \pm 0,08 \mathrm{a}$ & $8,57 \pm 0,72 \mathrm{a}$ \\
\hline $\mathrm{P} 2$ & $8,87 \pm 0,08 \mathrm{a}$ & $8,92 \pm 0,44 \mathrm{a}$ & $8,57 \pm 0,72 a$ & $8,92 \pm 0,44 a$ & $8,92 \pm 0,44 a$ \\
\hline $\mathrm{F}_{1}$ & $8,04 \pm 1,77 \mathrm{a}$ & $9,32 \pm 0,96 \mathrm{a}$ & $8,70 \pm 4,62 \mathrm{a}$ & $8,67 \pm 1,76 a$ & $11,11 \pm 2,68 \mathrm{a}$ \\
\hline $\mathrm{F}_{2}$ & $8,66 \pm 1,82 a$ & $8,57 \pm 0,82 \mathrm{a}$ & $10,80 \pm 1,04 \mathrm{a}$ & $9,29 \pm 3,56 a$ & $8,24 \pm 2,71 \mathrm{a}$ \\
\hline Mínimo & 6,57 & 7,38 & 5,43 & 6,58 & 5,45 \\
\hline \multirow[t]{2}{*}{ Máximo } & 11,00 & 10,35 & 11,97 & 14,13 & 13,00 \\
\hline & \multicolumn{5}{|c|}{ Fibra insolúvel (\%) } \\
\hline $\mathrm{P} 1$ & $27,44 \pm 2,15 \mathrm{a}$ & $27,44 \pm 2,15 \mathrm{a}$ & $26,77 \pm 0,91 \mathrm{a}$ & $26,77 \pm 0,91 \mathrm{a}$ & $24,82 \pm 0,52 \mathrm{a}$ \\
\hline $\mathrm{P} 2$ & $26,77 \pm 0,91 \mathrm{a}$ & $26,11 \pm 0,29 \mathrm{a}$ & $24,82 \pm 0,52 \mathrm{a}$ & $26,11 \pm 0,29 \mathrm{a}$ & $26,11 \pm 0,29 a$ \\
\hline $\mathrm{F}_{1}$ & $31,35 \pm 5,31 \mathrm{a}$ & $27,04 \pm 0,36 \mathrm{a}$ & $25,28 \pm 6,05 a$ & $28,11 \pm 4,43 a$ & $26,75 \pm 3,51 \mathrm{a}$ \\
\hline $\mathrm{F}_{2}$ & $27,83 \pm 2,62 \mathrm{a}$ & $29,09 \pm 2,82 \mathrm{a}$ & $25,88 \pm 3,61 \mathrm{a}$ & $26,55 \pm 3,01 \mathrm{a}$ & $29,77 \pm 3,13 a$ \\
\hline Mínimo & 24,82 & 25,90 & 21,00 & 22,22 & 24,27 \\
\hline Máximo & 35,10 & 32,60 & 29,69 & 31,24 & 33,88 \\
\hline & \multicolumn{5}{|c|}{ Fibra alimentar total (\%) } \\
\hline $\mathrm{P} 1$ & $37,44 \pm 1,65 \mathrm{a}$ & $37,44 \pm 1,65 \mathrm{a}$ & $35,63 \pm 0,99 a$ & $35,63 \pm 0,99 a$ & $33,39 \pm 0,19 \mathrm{~b}$ \\
\hline $\mathrm{P} 2$ & $35,63 \pm 0,99 a$ & $35,03 \pm 0,15 \mathrm{a}$ & $33,39 \pm 0,19 a$ & $35,03 \pm 0,15 \mathrm{a}$ & $35,03 \pm 0,15 \mathrm{~b}$ \\
\hline $\mathrm{F}_{1}$ & $39,39 \pm 3,54 a$ & $36,36 \pm 1,32 \mathrm{a}$ & $33,98 \pm 1,43 a$ & $36,77 \pm 2,67 \mathrm{a}$ & $37,86 \pm 0,83 \mathrm{a}$ \\
\hline $\mathrm{F}_{2}$ & $36,49 \pm 2,12 a$ & $37,65 \pm 3,08 \mathrm{a}$ & $36,69 \pm 3,23 a$ & $35,84 \pm 4,64 a$ & $38,01 \pm 3,47 a$ \\
\hline Mínimo & 33,46 & 34,92 & 32,74 & 31,99 & 33,10 \\
\hline Máximo & 41,89 & 41,29 & 39,50 & 42,44 & 41,26 \\
\hline & \multicolumn{5}{|c|}{ Rendimento de grãos (g por planta) } \\
\hline $\mathrm{P} 1$ & $10,35 \pm 2,74 \mathrm{a}$ & $10,35 \pm 2,74 \mathrm{a}$ & $11,54 \pm 1,46 \mathrm{a}$ & $11,54 \pm 1,46 \mathrm{a}$ & $13,08 \pm 5,72 \mathrm{a}$ \\
\hline $\mathrm{P} 2$ & $11,54 \pm 1,46 \mathrm{a}$ & $14,34 \pm 9,08 \mathrm{a}$ & $13,08 \pm 5,72 \mathrm{a}$ & $14,34 \pm 9,08 \mathrm{a}$ & $14,34 \pm 9,08 \mathrm{a}$ \\
\hline $\mathrm{F}_{1}$ & $11,61 \pm 1,34 \mathrm{a}$ & $9,80 \pm 3,39 a$ & $15,53 \pm 0,91 \mathrm{a}$ & $12,46 \pm 0,74 \mathrm{a}$ & $18,11 \pm 4,54 \mathrm{a}$ \\
\hline $\mathrm{F}_{2}$ & $12,22 \pm 2,17 \mathrm{a}$ & $14,38 \pm 4,22 \mathrm{a}$ & $13,08 \pm 3,70 \mathrm{a}$ & $15,02 \pm 2,35 \mathrm{a}$ & $17,54 \pm 2,81 \mathrm{a}$ \\
\hline Mínimo & 8,41 & 7,40 & 8,38 & 7,92 & 7,92 \\
\hline Máximo & 14,77 & 20,76 & 17,34 & 20,76 & 21,32 \\
\hline
\end{tabular}

(1)Médias seguidas de mesma letra, na vertical, não diferem a 5\% de probabilidade pelo teste de Tukey.

Tabela 3. Coeficientes de correlação de Pearson entre as características teor de fibra solúvel (FS), fibra insolúvel (FI), fibra alimentar total (FT) e rendimento de grãos, nas diferentes combinações e no conjunto das combinações.

\begin{tabular}{|c|c|c|c|}
\hline Característica & $\begin{array}{c}\text { FI } \\
(\%)\end{array}$ & $\begin{array}{l}\text { FT } \\
(\%)\end{array}$ & $\begin{array}{l}\text { Rendimento } \\
\text { (g por planta) }\end{array}$ \\
\hline & \multicolumn{3}{|c|}{ CNFP 8100 x FT 96-1282 } \\
\hline FS & \multirow[t]{3}{*}{$-0,68^{*}$} & $-0,29$ & $-0,32$ \\
\hline FI & & $0,89^{*}$ & 0,16 \\
\hline \multirow[t]{2}{*}{ FT } & & & 0,01 \\
\hline & \multicolumn{3}{|c|}{ CNFP 8100 x Varre -Sai } \\
\hline FS & \multirow[t]{3}{*}{$-0,16$} & 0,22 & $-0,30$ \\
\hline FI & & $0,93^{*}$ & 0,20 \\
\hline \multirow[t]{2}{*}{ FT } & & & 0,08 \\
\hline & \multicolumn{3}{|c|}{ FT 96-1282 x Valente } \\
\hline FS & \multirow[t]{3}{*}{$-0,59$} & 0,09 & $-0,19$ \\
\hline FI & & $0,75^{*}$ & 0,02 \\
\hline \multirow[t]{2}{*}{ FT } & & & $-0,13$ \\
\hline & \multicolumn{3}{|c|}{ FT 96-1282 x Varre-Sai } \\
\hline FS & \multirow[t]{3}{*}{$-0,20$} & 0,58 & 0,02 \\
\hline FI & & $0,68^{*}$ & $-0,23$ \\
\hline \multirow[t]{2}{*}{ FT } & & & $-0,18$ \\
\hline & \multicolumn{3}{|c|}{ Valente $\mathrm{x}$ Varre -Sai } \\
\hline FS & $-0,43$ & 0,30 & 0,01 \\
\hline FI & & $0,73^{*}$ & 0,53 \\
\hline \multirow[t]{2}{*}{$\mathrm{FT}$} & & & 0,57 \\
\hline & \multicolumn{3}{|c|}{ Geral } \\
\hline FS & $-0,48^{*}$ & 0,18 & $-0,06$ \\
\hline FI & & $0,78^{*}$ & 0,12 \\
\hline FT & & & 0,09 \\
\hline
\end{tabular}

*Significativo a 5\% de probabilidade, pelo teste t. indica que à medida que ocorre o aumento no teor de fibra insolúvel, ocorre também o incremento no teor de fibra alimentar total e que a seleção de genótipos de feijão, que agregam alto teor de fibra insolúvel e de fibra alimentar total, poderá ser efetiva.

Não foi encontrada associação entre as diferentes frações da fibra alimentar (solúvel, insolúvel e total) e o rendimento de grãos, pois os coeficientes de correlação de Pearson não foram significativos. Pode-se, portanto, sugerir que no programa de melhoramento seja priorizada a identificação de linhagens de feijão de alto potencial de rendimento de grãos e, só então, seja realizada a seleção para maior teor de fibra solúvel, insolúvel ou total, dependendo da necessidade das diferentes frações da fibra alimentar pelo mercado.

Considerando-se que os resultados obtidos não revelaram variabilidade genética para fibra solúvel, fibra insolúvel e para rendimento de grãos, nas diferentes populações obtidas, a seleção para esses parâmetros não terá eficiência pela ausência de variância genética (Tabela 4). Provavelmente, esses 
caracteres sejam quantitativos e, como conseqüência, muito influenciados pelo ambiente, o que resultou em menor contribuição da variância genética na expressão fenotípica.

Quanto ao conteúdo de fibra alimentar total, os maiores valores de variância fenotípica foram obtidos na combinação Valente x Varre-Sai, devido à maior variância genética encontrada nessa população (Tabela 4). Populações que apresentam variâncias genéticas superiores implicam em maiores diferenças entre os genótipos, o que é importante para a seleção.

A herdabilidade, em sentido amplo, fornece a proporção da variância genética presente na variância fenotípica total (Ramalho et al., 1993). Assim, coeficientes de herdabilidade mais altos podem ser associados com maior variância genética aditiva, menor variação do ambiente e menor interação genótipo x ambiente (Fehr, 1987). A combinação Valente x Varre-Sai é mais interessante para o melhoramento da fibra alimentar em feijão, pelo fato de possuir o mais alto coeficiente de herdabilidade no sentido amplo (97,03\%). Segundo
Carvalho et al. (2001), os caracteres com maior coeficiente de herdabilidade propiciam, através da seleção, maiores progressos genéticos. A seleção de genótipos, nessa população, poderá ser efetiva para o desenvolvimento de cultivares de feijão, que poderão ser utilizadas para a prevenção de doenças cardiovasculares e do trato intestinal, em virtude do maior teor de fibra alimentar presente nos grãos (Olson et al., 1987; Hughes, 1991; Moore, et al., 1998; Vanderhoof, 1998).

Considerando-se que o ganho por seleção é função da herdabilidade na geração em que as famílias foram avaliadas (Ramalho et al., 1993), a combinação que apresentou alta estimativa de herdabilidade foi também a de maior ganho por seleção (Tabela 5). Assim, destaca-se para fibra alimentar total, a combinação Valente $\mathrm{x}$ Varre-Sai (2,04\% de ganho). A seleção de plantas $F_{2}$, nessa população, pode resultar em genótipos com maior quantidade de fibra alimentar total, em função de o ganho esperado com a seleção ser considerado de alta magnitude para esse caracter em feijão.

Tabela 4. Parâmetros genéticos da fibra solúvel, fibra insolúvel, fibra alimentar total e rendimento de grãos de feijoeiro da população $\mathrm{F}_{2}$ em diferentes combinações.

\begin{tabular}{|c|c|c|c|c|c|}
\hline \multirow[t]{2}{*}{ Parâmetro } & \multicolumn{5}{|c|}{ Combinação } \\
\hline & CNFP 8100 x FT 96-1282 & CNFP 8100 x Varre-Sai & FT 96-1282 x Valente & FT 96-1282 x Varre-Sai & Valente x Varre-Sai \\
\hline & \multicolumn{5}{|c|}{ Fibra solúvel (\%) } \\
\hline Variância fenotípica & 3,2975 & 0,6684 & 1,0730 & 12,6390 & 7,3314 \\
\hline Variância genotípica & 1,6722 & 0,0967 & $-^{(1)}$ & 11,0393 & 3,5623 \\
\hline Herdabilidade ampla (\%) & 50,71 & 14,46 & - & 87,34 & 48,59 \\
\hline Valor máximo na $\mathrm{F}_{2}$ & 11,00 & 9,18 & 11,83 & 14,13 & 11,91 \\
\hline \multirow[t]{2}{*}{ Valor mínimo na $\mathrm{F}_{2}$} & 6,57 & 7,38 & 9,45 & 6,58 & 5,45 \\
\hline & \multicolumn{5}{|c|}{ Fibra insolúvel (\%) } \\
\hline Variância fenotípica & 6,8561 & 7,9562 & 13,0500 & 9,0871 & 9,7957 \\
\hline Variância de ambiente & 15,4601 & 1,2413 & 18,5917 & 10,0540 & 6,2399 \\
\hline Variância genotípica & - & 6,7150 & - & - & 3,5558 \\
\hline Herdabilidade ampla (\%) & - & 84,40 & - & - & 36,30 \\
\hline Valor máximo na $\mathrm{F}_{2}$ & 31,14 & 32,60 & 29,69 & 28,87 & 33,88 \\
\hline Valor mínimo na $\mathrm{F}_{2}$ & 24,82 & 26,12 & 22,15 & 22,22 & 27,04 \\
\hline \multicolumn{6}{|c|}{ Fibra alimentar total (\%) } \\
\hline Variância fenotípica & 4,5038 & 9,5000 & 10,4233 & 21,5100 & 12,0147 \\
\hline Variância genotípica & - & 7,9358 & 9,1491 & 17,6874 & 11,6579 \\
\hline Herdabilidade ampla (\%) & - & 83,53 & 87,78 & 82,23 & 97,03 \\
\hline Valor máximo na $\mathrm{F}_{2}$ & 38,17 & 41,29 & 39,50 & 42,44 & 41,26 \\
\hline Valor mínimo na $\mathrm{F}_{2}$ & 33,46 & 35,05 & 32,74 & 31,99 & 33,10 \\
\hline \multicolumn{6}{|c|}{ Rendimento de grãos (g por planta) } \\
\hline Variância fenotípica & 4,7046 & 17,8202 & 13,6955 & 5,5101 & 7,8751 \\
\hline Variância de ambiente & 3,3053 & 28,2260 & 9,1275 & 21,4091 & 39,0933 \\
\hline Variância genotípica & 1,3994 & $-10,4058$ & 4,5680 & - & - \\
\hline Herdabilidade ampla (\%) & 29,74 & - & 33,35 & - & - \\
\hline Valor máximo na $\mathrm{F}_{2}$ & 14,77 & 18,68 & 17,34 & 18,04 & 20,40 \\
\hline Valor mínimo na $\mathrm{F}_{2}$ & 9,49 & 9,09 & 8,38 & 12,43 & 13,84 \\
\hline
\end{tabular}

(1)Variância negativa. 
Tabela 5. Predição de ganhos por seleção, considerando-se as duas linhas $F_{2}$ de maior valor de fibra solúvel, fibra insolúvel, fibra alimentar total e rendimento de grãos obtidos em diferentes combinações.

\begin{tabular}{|c|c|c|c|c|c|}
\hline \multirow[t]{2}{*}{ Parâmetro } & \multicolumn{5}{|c|}{ Combinação } \\
\hline & $\begin{array}{c}\text { CNFP } 8100 x \\
\text { FT 96-1282 }\end{array}$ & $\begin{array}{c}\text { CNFP } 8100 \text { x } \\
\text { Varre-Sai }\end{array}$ & $\begin{array}{c}\text { FT 96-1282 x } \\
\text { Valente }\end{array}$ & $\begin{array}{l}\text { FT 96-1282 x } \\
\text { Varre-Sai }\end{array}$ & $\begin{array}{l}\text { Valente } \mathrm{x} \\
\text { Varre-Sai }\end{array}$ \\
\hline & \multicolumn{5}{|c|}{ Fibra solúvel $(\%)$} \\
\hline Linhas selecionadas em $\mathrm{F}_{2}$ & 4 e 2 & 1 e 3 & 1 e 3 & 2 e 1 & 1 e 2 \\
\hline Média original da $\mathrm{F}_{2}$ & 8,66 & 8,57 & 10,80 & 9,29 & 8,24 \\
\hline Média das linhas selecionadas & 9,82 & 9,10 & 11,59 & 11,95 & 10,06 \\
\hline Diferencial de seleção & 1,16 & 0,53 & 0,78 & 2,67 & 1,82 \\
\hline Ganho por seleção & 0,59 & 0,08 & $-7,11$ & 2,33 & 0,88 \\
\hline Ganho por seleção (\%) & 6,78 & 0,90 & $-65,83$ & 25,07 & 10,74 \\
\hline \multirow[t]{2}{*}{ Média predita para $1^{\circ}$ ciclo após seleção } & 9,25 & 8,64 & 3,69 & 11,61 & 9,12 \\
\hline & \multicolumn{5}{|c|}{ Fibra insolúvel (\%) } \\
\hline Linhas selecionadas em $\mathrm{F}_{2}$ & $1 \mathrm{e} 3$ & 2 e 1 & 4 e 3 & 3 e 2 & 3 e 2 \\
\hline Média original da $\mathrm{F}_{2}$ & 27,83 & 29,09 & 25,88 & 26,55 & 29,77 \\
\hline Média das linhas selecionadas & 29,67 & 31,28 & 28,93 & 28,59 & 32,20 \\
\hline Diferencial de seleção & 1,83 & 2,19 & 3,04 & 2,04 & 2,43 \\
\hline Ganho por seleção & $-2,30$ & 1,85 & $-1,29$ & $-0,22$ & 0,88 \\
\hline Ganho por seleção (\%) & $-8,26$ & 6,35 & $-4,99$ & $-0,82$ & 2,96 \\
\hline \multirow[t]{2}{*}{ Média predita para $1^{\circ}$ ciclo após seleção } & 25,53 & 30,93 & 24,59 & 26,33 & 30,65 \\
\hline & \multicolumn{5}{|c|}{ Fibra alimentar total (\%) } \\
\hline Linhas selecionadas em $\mathrm{F}_{2}$ & 4 e 1 & 2 e 1 & 3 e 4 & 2 e 3 & 3 e 1 \\
\hline Média original da $\mathrm{F}_{2}$ & 36,49 & 37,65 & 36,69 & 35,84 & 38,01 \\
\hline Média das linhas selecionadas & 37,94 & 40,21 & 39,32 & 38,99 & 40,11 \\
\hline Diferencial de seleção & 1,45 & 2,56 & 2,64 & 3,15 & 2,10 \\
\hline Ganho por seleção & $-0,87$ & 2,14 & 2,31 & 2,59 & 2,04 \\
\hline Ganho por seleção (\%) & $-2,38$ & 5,67 & 6,30 & 7,23 & 5,36 \\
\hline \multirow[t]{2}{*}{ Média predita para $1^{\circ}$ ciclo após seleção } & 35,62 & 39,79 & 39,00 & 38,43 & 40,04 \\
\hline & \multicolumn{5}{|c|}{ Rendimento de grãos (g por planta) } \\
\hline Linhas selecionadas em $\mathrm{F}_{2}$ & $1 \mathrm{e} 2$ & 3 e 2 & 4 e 2 & $1 \mathrm{e} 4$ & 3 e 2 \\
\hline Média original da $\mathrm{F}_{2}$ & 12,22 & 14,38 & 13,08 & 15,02 & 17,54 \\
\hline Média das linhas selecionadas & 13,67 & 17,68 & 15,63 & 16,70 & 19,60 \\
\hline Diferencial de seleção & 1,46 & 3,30 & 2,55 & 1,68 & 2,06 \\
\hline Ganho por seleção & 0,43 & $-1,93$ & 0,85 & $-4,84$ & $-8,16$ \\
\hline Ganho por seleção (\%) & 3,54 & $-13,41$ & 6,50 & $-32,23$ & $-46,49$ \\
\hline Média predita para $1^{\circ}$ ciclo após seleção & 12,65 & 12,45 & 13,93 & 10,18 & 9,39 \\
\hline
\end{tabular}

\section{Conclusões}

1. Há correlação fenotípica positiva entre os caracteres fibra insolúvel e fibra alimentar total.

2. A seleção de plantas $F_{2}$ em populações segregantes, desenvolvidas a partir do cruzamento Valente x Varre-Sai, pode ser efetiva no desenvolvimento de germoplasma de feijão com maior teor de fibra alimentar total, em virtude da maior herdabilidade e ganho por seleção obtidos.

\section{Referências}

AOAC INTERNATIONAL (Gaithersburg, Estados Unidos). Official methods of analysis of AOAC International. $16^{\text {th }}$ ed. Washington, 1995. 200p.

BECKER, H.G.; STELLER, W.; FELDHEIN, W.; WISKER, E.; KULIKOWSKI, W.; SUCKOW, P.; MEUSER, F.; SEIBEL, W.
Dietary fiber and bread: intake, enrichment, determination and influence on colonic function. Cereal Foods World, v.31, p.306310, 1986.

BRASIL. Ministério da Agricultura, Pecuária e Abastecimento. Anexo IV. Requisitos mínimos para determinação do valor de cultivo e uso de feijão (Phaseolus vulgaris), para a inscrição no registro nacional de cultivares - RNC. Disponível em: <http:// www.agricultura.gov.br>. Acesso em: 7 fev. 2005.

CARVALHO, F.I.F. de; SILVA, S.A.; KUREK, A.J.; MARCHIORI, V.S. Estimativas e implicações da herdabilidade como estratégia de seleção. Pelotas: Ufpel, 2001. 98p.

CEPEF. Indicações técnicas para a cultura do feijão no Rio Grande do Sul 2003/04. Passo Fundo: UPF, 2003. 149p.

COIMBRA, J.L.M.; GUIDOLIN, A.F.; CARVALHO, F.I.F. de. Parâmetros genéticos do rendimento de grãos e seus componentes com implicações na seleção indireta em genótipos de feijão preto. Ciência Rural, v.29, p.1-6, 1999.

CRUZ, C.D. Programa genes: versão Windows, aplicativo computacional em genética e estatística. Viçosa: UFV, 2001. 648p. 
CRUZ, C.D.; REGAZZI, A.J. Modelos biométricos aplicados ao melhoramento genético. 2.ed. Viçosa: UFV, 1997. 390p.

EGG MENDONÇA, C.V.C. Caracterização química e enzimática de famílias de feijões obtidas do cruzamento das linhagens amarelinho e CI-107. 2001. 48p. Dissertação (Mestrado) Universidade Federal de Lavras, Lavras.

FEHR, W.R. Principles of cultivar development. Iowa: Macmillan, 1987. v.1, 768p.

GUERRA, N.B.; DAVID, P.R.B.S.; MELO, D.D. de; VASCONCELOS, A.B.B.; GUERRA, M.R.M. Modificações do método gravimétrico não enzimático para determinar fibra alimentar solúvel e insolúvel em frutos. Revista de Nutrição, v.17, p.45-52, 2004.

HOSFIELD, G.L. Genetic control of production and food quality factors in dry bean. Food Technology, v.45, p.98-103, 1991.

HUGHES, J.S. Potential contribution of dry bean dietary fiber to health. Food Technology, v.45, p.122-126, 1991.

LONDERO, P.M.G.; RIBEIRO, N.D.; RODRIGUES, J.A.; POERSCH, N.L.; TRENTIN, M. Genetic variability for dietary fiber content in common bean populations. Crop Breeding and Applied Biotechnology, v.5, p.86-90, 2005.

MESQUITA, I.A. Efeito materno na determinação do tamanho da semente do feijoeiro (Phaseolus vulgaris L.). 1989. 70p. Dissertação (Mestrado) - Universidade Federal de Lavras, Lavras.

MOORE, M.A.; PARK, C.B.; TSUDA H. Soluble and insoluble fiber influences on cancer development. Critical Reviews in Oncology/Hematology, v.27, p.229-242, 1998.
MORROW, B. The rebirth of legumes. Food Technology, v.45, p.96-121, 1991.

MUTSCHLER, M.A.; BLISS, F.A. Inheritance of bean seed globulin content and its relationship to protein content and quality. Crop Science, v.21, p.289-294, 1981.

OLIVEIRA, L.F.A.; OLIVEIRA, M.G.A.; COSTA, N.M.B.; COELHO, D.T. Teores de fibra alimentar e de inibidores de proteases em arroz polido (Oriza sativa L.) e feijão comum (Phaseolus vulgaris L.). Brazilian Journal of Food Technology, v.2, p.161-165, 1999.

OLSON, A.; GRAY, M.G.; CHIU, M.C. Chemistry and analysis of soluble dietary fiber. Food Technology, v.4, p.71-82, 1987.

PETERNELLI, L.A.; BORÉM, A. Hibridação em feijão. In: BORÉM, A. (Ed.). Hibridação artificial de plantas. Viçosa: UFV, 1999. p.269-294.

RAMALHO, M.A.P.; SANTOS, J.B.; PINTO, C.A.B.P. Genética na agropecuária. Lavras: Ufla, 2000. 472p.

RAMALHO, M.A.P.; SANTOS, J.B.; ZIMMERMANN, M.J. de O. Genética quantitativa em plantas autógamas: aplicações ao melhoramento genético do feijoeiro. Goiânia: UFG, 1993. 271p.

SCHNEEMAN, B.O. Dietary fiber: a scientific status summary by the Institute of Food Technologists' Expert Panel on Food Safety \& Nutrition. Food Technology, v.43, p.133-139, 1989.

TOPPING, D.L. Soluble fiber polysaccharides: effects on plasma cholesterol and colonic fermentation. Nutrition Reviews, v.49, p.195-203, 1991.

VANDERHOOF, J.A. Immunonutrition: the role of carbohydrates. Nutrition Research, v.14, p.595-598, 1998. 